\title{
Shifts in Collocational Preferences
}

Welcome back to Ten Lectures on Diachronic Construction Grammar. In the lecture this morning, one of the issues that I was concerned with was the open question in Diachronic Construction Grammar of how we can make our analysis more focused on the connections between constructions, rather than maintaining a focus on the internal structure of the nodes in that network. I called that the "fat node problem". To address that problem, I have discussed the example of the English auxiliary may, which has over time come to be used with a very different set of lexical collocates. You remember the journey of may in the system of modals that reflects its changing connections with the lexical constructions that it occurs with. In this lecture, I want to expand on the issue of shifts in collocational preferences. I want to discuss a number of case studies that allow us to assess the theoretical conclusions that we can draw from observing shifts of this kind.

One important point is that in the development of grammatical constructions, these collocational shifts are not just random events. In the lexical domain, by contrast, anything can happen. You remember from yesterday the collocate display of gay, and its early collocates like gay colours and its later collocates like gay community. The collocational shifts show us that some meaning change has taken place, but there aren't any broader implications of this beyond that. This is what happened to the adjective gay, and other lexical elements may change in completely different ways.

With grammatical constructions, however, shifts and collocates tend to reflect more systematic patterns of change, such as the ones proposed by grammaticalization theory.

Remember also the proposal by Traugott and Trousdale (2013) that grammatical constructionalization involves an increase in schematicity. We expect grammatical constructions to broaden in their collocational behavior over time. We expect them to occur with more types of lexical elements. We expect

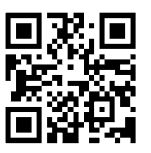

All original audio-recordings and other supplementary material, such as any hand-outs and powerpoint presentations for the lecture series, have been made available online and are referenced via unique Dor numbers on the website www.figshare.com. They may be accessed via this QR code and the following dynamic link: https://doi.org/10.6o84/mg.figshare.13691059. 
- Israel, Michael. 1996. The way constructions grow. In Adele E.

Goldberg (ed.), Conceptual structure, discourse and language, 217-30.

Stanford: CSLI Publications.

The demonstrators pushed their way into the building.

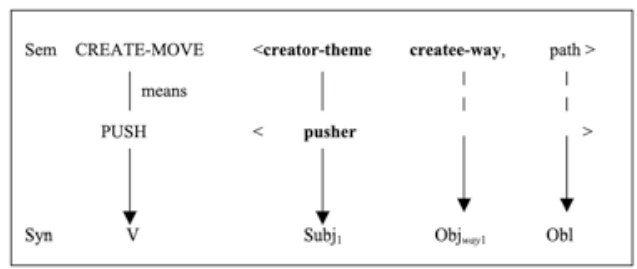

Goldberg (1995: 208; Figure 9.2)

FIGURE 1

these types to have different meanings, or an increasing range of lexical meaning. That is the kind of phenomenon that I want to look at in this lecture. With all of that in mind, let's get on the way. Coincidentally, what got me on my way with regard to Diachronic Construction Grammar was a paper by Michael Israel (1996) with the curious title "The Way Constructions Grow". This title very cleverly blends two ideas. On the one hand, the paper addresses by now well-known pattern that is called the way-construction. It presents a study of way-constructions and how these constructions grow. At the same time, the paper explains how this process unfolded, as it discusses the way in which constructions grow. It is terrible of me to explain the joke, you simply have to forgive me.

What you see on the slide is an example and a representation of the wayconstruction, taken from the work of Adele Goldberg (1995). The example is "The demonstrators pushed their way into the building". The diagram, the box with the semantics and syntax and the arrows and the arguments, that is meant to capture that the construction can take a verb such as push, that has the meaning of creating something and moving something at the same time. The construction adds two arguments that are not normally called for by the verb. That is what the dotted lines mean. Push requires a pusher, i.e. the subject. But the two other constituents are actually added by the construction. They are not part of the ordinary argument structure of the verb. The first of the two arguments that are added by the construction is an object that encodes a created way. Goldberg calls this the createe-way argument. Then there is a 
prepositional phrase, Goldberg calls it the path here, that expresses either a path or a location. In this case, it is a path: "into the building".

How did Michael Israel analyze this construction? His starting point is an observation that Goldberg made about the construction. The construction is polysemous. It can express two basic ideas. It can express manner of motion as well as a means of motion. Manner of motion is expressed in examples such as "The wounded man limped his way across the field". The movement is carried out in a limping, effortful manner. By contrast, in an example such as "Joe cheated his way into law school", cheating is a means to achieve a result. There is a metaphorical movement. Joe is metaphorically moving into law school and cheating allows the subject to carry out that movement. The way-construction is what Goldberg calls an argument structure construction, which is to say that in synchronic usage, the construction can modify the argument structure of the verb that it takes. It imposes an unusual argument structure on the verb, in these examples the verbs limp and cheat. You notice that I can use the verbs limp and cheat intransitively. I can say "The man was limping" or "John, he is always cheating". There are other argument structures that go with these verbs, but I can use them intransitively, and the way-construction allows me to use new and additional arguments with these verbs, namely a created way argument and a path or a goal argument.

Michael Israel looked at this construction by tracing its usage history in historical texts. He used a particular data resource for this, the Oxford English Dictionary, which is a dictionary that not only lists words and definitions. It also provides authentic bits of texts that illustrate how these words are used. What he found was that all the examples from the Oxford English Dictionary show that the construction established itself first with verbs that encode paths. What he found was that the early manner interpretation corresponds to examples with general motion verbs. Here is an example of this, "The kyng took a laghtre and wente his way". Went is just the past tense of go, a movement verb, the king laughed and went his way. The construction thus emerges in a very specific lexical context with verbs that harmonize with the overall meaning of the construction. That is not only true of the manner interpretation. It is also true of the means interpretation. Here the construction is used early on with verbs that explicitly encode the creation of path. Here we have an example, "Arminius paved his way". You pave the surface and after that you have a way to move along on.

Now, looking at these examples at this stage, you could argue that the way-construction has not fully constructionalized in the sense of Traugott and Trousdale, but rather what we have here is a more or less transparent 
compositional use of a particular argument structure and verbs that harmonize with that argument structure. This, if you like, is the way-construction coming into being, constructionalizing in the sense of Traugott and Trousdale.

As time goes on, the construction goes through a type frequency increase. More and more different verb types occur in that particular argument structure pattern with the manner interpretation. Michael Israel counted all the verbs. Up to 1700 , the manner interpretation is relatively sparse in the data. There are only 16 different verb types, including go, pass, run and a few others. Then, from the 19th century onward, there are 38 more that he finds. Worm here means to move like a worm. Fumble is a slow and clumsy movement. With regard to means, this starts earlier, so Israel finds examples as early as 165 o. There we have the path-creation verbs such as pave or smooth or cut. You cut your way through a jungle or through some difficult terrain. Later on in the 18th century, he finds verbs that metaphorically extend this kind of path-creating idea. There is battle, there is fight. Then from the late 19th century onward, we find verbs that we find also nowadays in the way-construction, verbs like elbow, shoot, spell, and even things like write. You can "write your way out of a difficult situation". You've offended someone and you write them an apology. You can write your way out of a hot mess that you've gotten yourself into. The increasing type frequency maps onto increasing degrees of schematicity and abstraction. This instantiates one of the pathways that Traugott and Trousdale proposed for grammatical constructionalization, i.e. increases in productivity, increases in schematicity, and decreases in compositionality. When we have something like "He elbowed his way out of the subway", the meaning component of difficult laborious motion is carried holistically by the entire construction, rather than by any individual element on its own. When I read Michael Israel's paper, I took away three lessons. Those lessons for me were the following.

First of all, I understood that constructionalization happens in the context of particular collocations. There are certain words and constructions that are used together. This starts the process. Second, shifts in collocational preferences reflect changes in constructional meaning. As we use a construction with more and more different verbs, our idea of what this construction can do changes along with it. Constructional change, and that is the third conclusion, shows itself in changing relative frequencies and type frequencies of lexical collocates, not necessarily in their absolute frequencies. One curious thing about the way-construction is that for the longest time, make actually has been the most frequent verb in this construction. That has been relatively constant. But there have been a lot of developments going on under the surface of the most frequent elements. 
There is one further conclusion from the paper that I would like to read to you in the words of Michael Israel himself. This captures very much the way I have come to think about constructional change. Here it is.

The way-construction emerged gradually over the course of several centuries. There is no single moment we can point to and say, "This is where the construction entered the grammar.' Rather, a long process of local analogical extensions led to a variety of idiomatic usages to gradually gain in productive strength even as they settled into a rigid syntax. As the range of predicates spread, increasingly abstract schemas could be extracted from them and this in turn drove the process of increasing productivity.

Here Michael Israel actually prefigures the main aspects of Traugott and Trousdale's concept of constructionalization, with its aspects of compositionality, schematicity and productivity. More specifically, the development of the way-construction clearly illustrates the phenomenon of what I talked about as host-class expansion yesterday and earlier today. I would say that Michael Israel's paper on the way-construction was one major inspiration for the research that I then did in my doctoral dissertation.

In my dissertation, I investigated future tense constructions across a range of languages from the Germanic family. The main overarching aim of that book was to see if we can use shifting collocational preferences to study on-going semantic change. Here is where the theoretical parts of what I have been talking about so far meet the methodological parts. I chose future constructions for my study because a lot is known about the grammaticalization of future tense markers. They tend to come from a handful of lexical sources such as movement verbs (English be going to), verbs of desire (English will, which derives from a verb meaning 'want' and 'desire'), or verbs of obligation (English shall falls into that category). There are verbs that mean 'turn' or 'change'. There is no English construction for that, but German has one, namely werden, which meant 'turn' originally. There are verbs that express intentions or at least relate to intentions. Swedish, for example, has a future construction with a verb that means 'think'. When I say I think going to the movies, it over time turns into an expression that tells my interlocutor I will be going to the movies later today.

Grammaticalization scholars have proposed very specific developmental pathways for these constructions. Movement verbs are known to turn into markers of intention, and after that into markers of future time, and after that into yet other meanings. I was curious to see whether these proposed grammaticalization pathways could be shown to be reflected in historically shifting 
patterns of collocations. This turned out to be true. You can actually see these trajectories.

My study compares future constructions from five different Germanic languages. It is based on historical corpus data exploring both the synchronic meaning and the historical development of these future constructions. It applies a method that I briefly talked about this morning, collostructional analysis. I will say more about this as we go along here. The method allows us to measure how a particular future marker is connected to lexical verbs that occur with it. It allows us to determine what associations exist and how strong they are.

More importantly, we can also use it to investigate how these patterns of association change over time. Michael Israel looked at this from a qualitative point of view. He took examples from different historical periods. He noted what kind of verbs came first, what kind of verbs were added later, and how the changes reflected increasing degrees of productivity. When I say from a qualitative point of view, that is not entirely true. He did count the types, but that very much stays at the level of descriptive statistics, not inferential techniques.

In my studies, I have been fortunate to have two great teachers and mentors, Anatol Stefanowitsch and Stefan Gries, who developed a technique for the analysis of collocational relations between constructions and lexical items. This method became available just when I needed it. It fell into my lap at the exactly right time. I am of course talking about collostructional analysis. This is a method that allows you to quantify how strongly a set of lexical items is associated with a grammatical construction that has an open slot for these lexical items. Stefanowitsch and Gries developed collostructional analysis for the study of such associations in synchronic present-day usage. But one day, when I was riding my bicycle home from university, I wondered whether it would be possible to tweak the method just a little bit, so that I could use it to study change over time.

I wrote an email to Anatol later that day and asked him whether he thought it could be done. He emailed me back and told me to try it. As a dutiful student, I followed his advice. I developed the idea and publish a short paper with the title "Distinctive Collexeme Analysis and Diachrony" (Hilpert 2006), and in the same issue of the journal then Anatol published a short reply (Stefanowitsch 2006), summarizing all the points that he found problematic about it. I am getting ahead of myself here. Let me explain what collostructional analysis is all about.

The basic idea is one that I mentioned in lecture one, namely that constructional meaning is reflected in associations between syntactic patterns and lexical elements. The fact that give is the most frequent verb in the ditransitive 


\section{Raw frequencies are often not enough}

- Collocate frequencies of will and be going to in the BNC
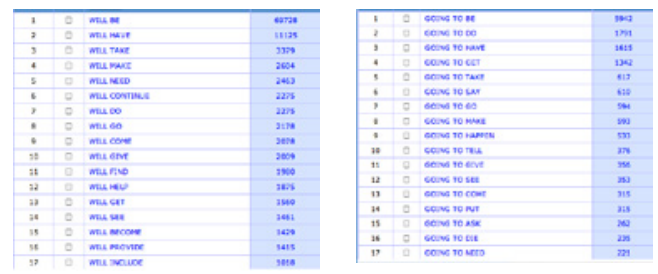

- Sometimes it is not enough to compare raw frequencies - we need to find out which lexical elements occur more often than expected with a construction.

FIGURE 2

construction, and the fact that we find the verb elbow in the way-construction, that illustrates this harmony in meaning between grammatical constructions and the lexical items that occur within them. Let me just read this to you again. Stefanowitsch and Gries (2003: 236) motivate this in the following way: "If syntactic structures served as meaningless templates waiting for the insertion of lexical material, no significant associations between these templates and specific verbs would be expected". But no matter where we look, pretty much any syntactic pattern that has been investigated in this way shows asymmetries that demonstrate that these distributions differ from chance in many ways. There is no random distribution of lexical elements across syntactic constructions.

This also relates to the controversy of collostructional analysis versus raw frequencies. This is actually a good moment to explain what is really at the heart of this controversy. Sometimes it will turn out that when you look at the lexical elements in a grammatical construction, the raw frequencies won't tell you a great deal. Sometimes looking at raw frequencies is just not enough. As an example for that, this slide presents two lists of collocate frequencies from two near-synonymous grammatical constructions of English, namely the English will future and the English be going to future, and the most frequent lexical verbs that occur within them. If you go through these two lists, you notice that they are almost identical. We start with very frequent verbs like will be, will have, will take, will make and so on and so forth. With going to, we have going to be, going to do, going to have, going to get. Basically, you're just getting these long lists of semantically light, very general, very frequent verbs. You might look at these two lists and conclude that they are almost indistinguishable. These two constructions have similar functions, so they occur with similar sets 
of verbs. However, if we find out which elements are not only frequent, but actually more or less frequent than expected, then we can say something more about these constructions. I mentioned collostructional analysis briefly earlier this morning. Let me go back to this and explain the general logic.

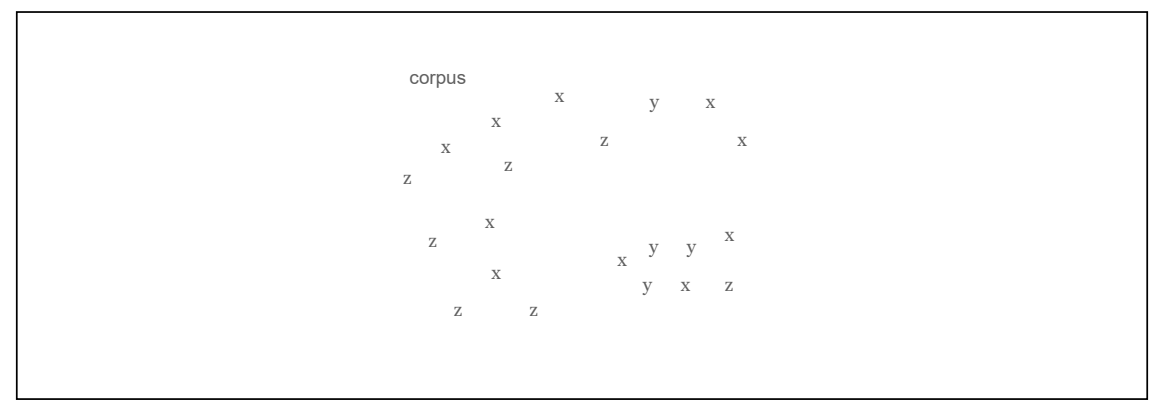

FIGURE 3

Let's say that you have a corpus that has lots and lots of different word types in it. Here I have symbolized them with letters $x, y$ and $z$. Let's say that you extract from that corpus all the instances of a construction and count the lexical elements that you find in that construction. In this case, we have a very small sample.

\section{Raw frequencies}

\section{FIGURE 4}

The construction occurs with seven lexical items. These seven lexical items fall into three types, $x, y$ and $z$. Three times $x$, three times $y$, and one $z$. If we were to stay with these raw frequencies, we would say that, for this construction, $x$ and $y$ are of approximately equal importance.

However, as soon as we compare the frequencies of these items within the construction to the frequencies of these items outside of the construction in the corpus, it becomes apparent that $x$ is an element that we find throughout 


\section{Collostructional analysis}

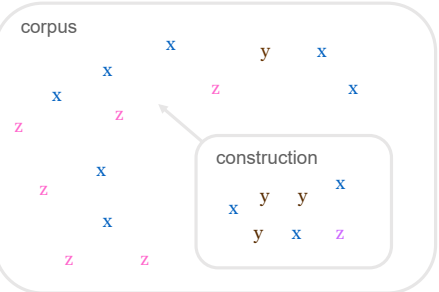

FIGURE 5

the corpus with high frequency. This is in contrast to $y$, which we find three times in the construction, but only once in other contexts. This would be similar to the case of elbow in the way-construction. Elbow is a very infrequent verb. To the extent that we find it in a corpus, it will tend to appear in the wayconstruction, but not anywhere else, at least not very frequently.

This, in a nutshell, brings me to the controversy between collostructional analysis and raw frequencies. The view of focusing on raw frequencies only chooses to ignore how often a lexical element appears not only in the construction, but also in the corpus as a whole.

I have a quote from Gries et al. (2005: 665) here, where they say, "Arguing and theorizing on the basis of mere frequency data alone runs a considerable risk of producing results which might not only be completely due to the random distribution of words [in a corpus], but which may also be much less usage-based than the analysis purports to be." It may be questionable to say that words in a corpus are randomly distributed. Language does not work that way, but the point stands that we want to account for these occurrences that occur outside of the construction. Gries et al. (2005) have done empirical work that supports the better adequacy of collostructional results over raw frequencies. Let me review that for a minute.

When we have a verb as a cue for a construction, what is it that determines the validity or the usefulness of that cue? According to Bybee's view, the most frequent verb that appears in a construction should be the best cue for that construction. According to Stefanowitsch and Gries (2003), it might not be the most frequent verb, it might be the verb that is most strongly attracted to the construction that provides the best cue, even if that verb is not very frequent. If all of its instances are found with the construction, as in the case of elbow and the way-construction, that would make for a very reliable, very useful cue. 
Let me give you an example. The most frequent verb in the way-construction is the verb make. Now, when I say I made, does that make you think of the way-construction? Does it make you want to continue that sentence with my way through the city? I made can be continued in lots of other ways. I made a mistake, I made her a sandwich, and lots of other things. It is not the best cue for the way-construction.

By contrast, the verb elbow, if I start an utterance with I elbowed, there are not many ways to continue that sentence. I elbowed my way out of the subway, that would be a very natural continuation of that sentence fragment. This is the methodology that Gries and colleagues applied to investigate which verbs in a carrier phrase would prompt speakers to continue with a specific construction. The construction that they used as an example is a construction that they called the English as-predicative construction. It is instantiated by sentences such as "The idea was perceived as too radical". We have a verb like perceive, and then a prepositional phrase with as, and a certain predicate, so radical is predicated over the idea.

Here are three examples of the as-predicative construction: The proposal was considered as rather provocative; I had never seen myself as being too thin; California is perceived as a place where everything is possible. There are different verbs that appear in this construction. One of them is the verb see, as in sentence fragments such as I have never seen or I had never seen., which you could continue that with the as-predicative. Some verbs give you a very strong cue, like the verb hail. When I start a sentence fragment with The idea was hailed, the as-predicative almost forces itself upon my mind. So, some verbs make you think about the as-predicative in very direct ways, and other verbs do not. The question now is which verbs are which. What determines cue validity? Is it frequency in the construction, or is it attraction to the construction that we measure via collostructional analysis?

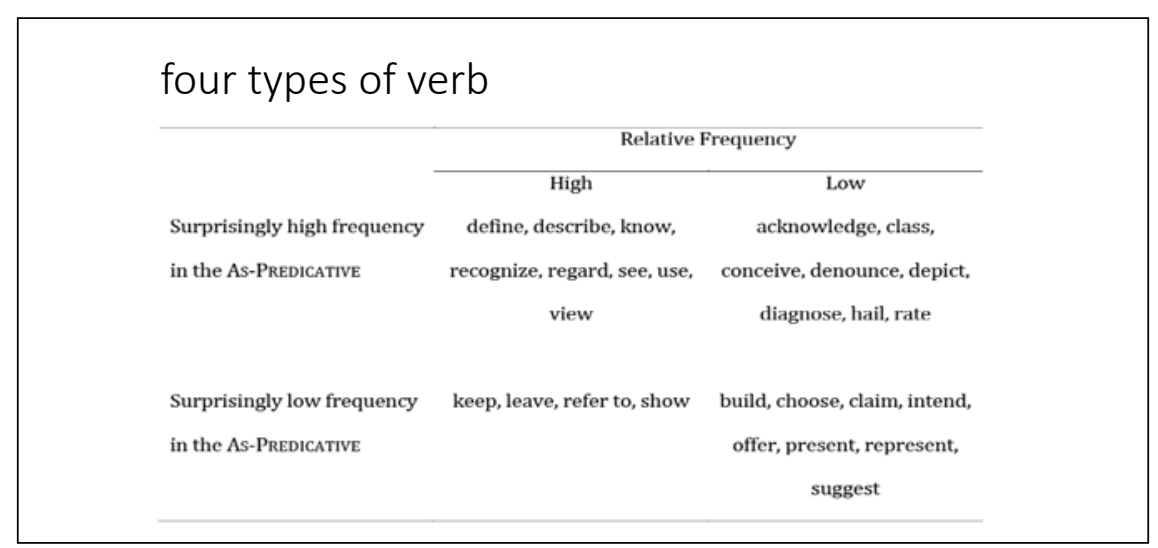

FIGURE 6 
Gries and colleagues compared four different types of verb for their design. First, they took sets of verbs that are generally frequent in English. These are verbs such as define, describe, know, recognize and verbs like keep, leave, refer to and show. Some of them are surprisingly frequent in the as-predicative, for example define and describe. Some of them are very frequent in general but surprisingly infrequent in the as-predicative. This is true for keep, as in He was kept as a slave. That does not appear very often. In the right column of this table, you see verbs that are low in frequency. Some of them are surprisingly frequent in the as-predicative, for instance conceive. It is not a very frequent verb, but I can say "This was conceived as the solution for that problem". Depict is another surprisingly frequent collocate, and hail is yet another one. Finally, some verbs are infrequent in general, and also surprisingly infrequent in the as-predicative construction. This includes suggest, "This was suggested as a possible solution".

On the raw frequency view, high frequency verbs should pattern alike, no matter whether they are surprisingly frequent or surprisingly infrequent in the as-predicative When speakers see a sentence fragment with a high frequency verb, there should be a high probability that they continue the fragment with the as-predicative.

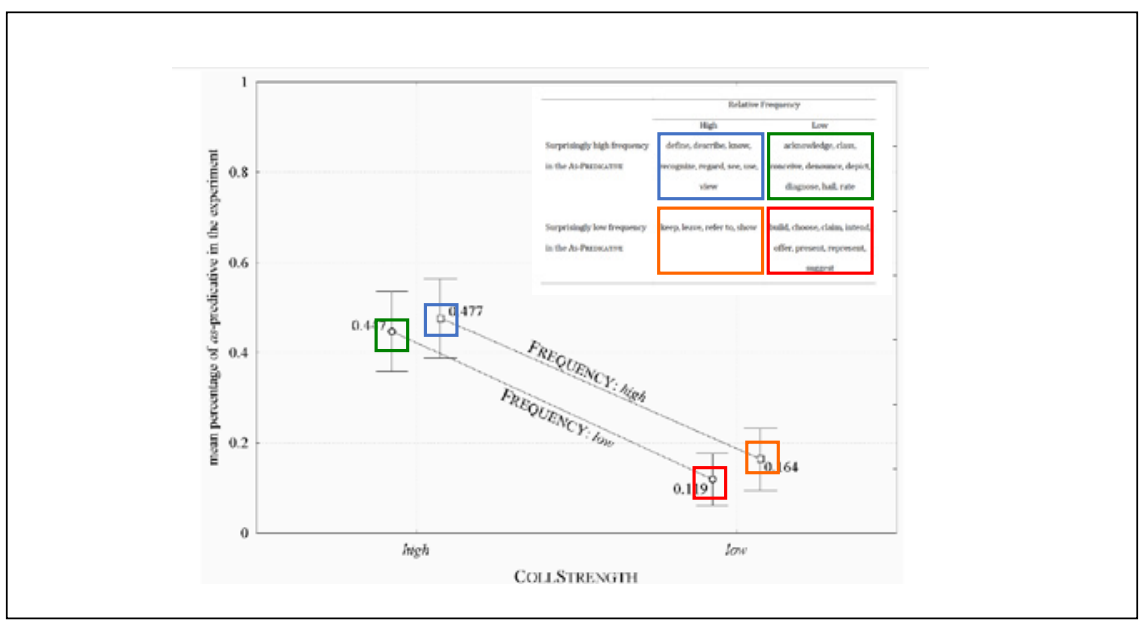

FIGURE 7

On the collostructional hypothesis, however, attraction to the as-predicative should matter more than just raw frequency. The verbs that are surprisingly frequent in the as-predicative should pattern together with low frequency verbs such as hail and depict. That means that when speakers see a sentence fragment with these verbs, they should be more likely to continue the fragment with an as-predicative construction. 
Here's what came out of the experiment. Here you see a chart (Gries et al. 2005: 659) that shows the rate of completion with an as-predicative construction that was obtained in the experiment. The $y$-axis shows you how many of the participants chose to continue a given sentence fragment with the aspredicative. You see that there are two types of verb that are higher up and two types of verb further down.

Higher up you see the verbs that are strongly associated with the construction. There are the frequent verbs and the infrequent verbs, but both of them are surprisingly over-represented in the construction. Down below you see the verbs that are not strongly associated with the construction. If we look at the orange box here, these verbs are frequent in the as-predicative. Bybee would predict that those should trigger a lot of completions with the construction, but it does not. There are not many completions with the as-predicative. Up here is the green box. These verbs are infrequent in the as-predicative, but they are strongly associated with them. This would be similar to the case of elbow in the way-construction. For the as-predicative, it is hail. It is not very frequent, neither inside nor outside the construction, but when you see hail, then it is a very reliable cue for the as-predicative.

In summary, collostructional strength, the strength of association between a construction and a lexical item, matters. Raw frequencies matter too. You see that the frequent verbs are slightly above the infrequent verbs, but that is a secondary factor.

Let me come back to how collostructional analysis works. What I have shown you so far is what is known as collexeme analysis, the basic type of collostructional analysis that compares frequency within a construction against lexical item frequency in the corpus as a whole.

\section{Collostructional analysis}

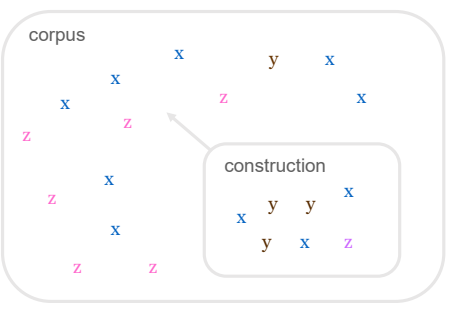

FIGURE 8 
The analysis type that I briefly discussed this morning is distinctive collexeme analysis, where we compare collocate frequencies across two different constructions. We have construction $\mathrm{A}$, which has a number of collocates with different frequencies. We have construction $B$ with the same types at different frequencies. We can figure out which elements are maximally uneven in their distributions. Which elements have the greatest frequency asymmetry between construction A and construction B? That can give us a cue as to what makes these two constructions different. That kind of contrast, that kind of analysis makes sense when we are dealing with constructions that are related in some way, that have similar functions like will and be going to. Or think of different complementation patterns, that-clauses and ing-clauses, or the get-passive and the passive with $b e$. You could also contrast broader tense patterns like the simple present and the present progressive. That would show you the different collocational preferences that these construction types have. Depending on the level of abstraction of these constructions, there are different observations you could make. So far, I have presented the synchronic way of conducting collostructional analysis. Let me get to its diachronic application.

The idea that I had on my bicycle, going home from university, was that we have a diachronic corpus with data from different historical periods, for example starting in the 16oos, then the 1700 s and then 1800 s and so on and so forth. We look for the same construction across different time slices of the same corpus. That enables us to identify asymmetries across these time slices.

A diachronic application

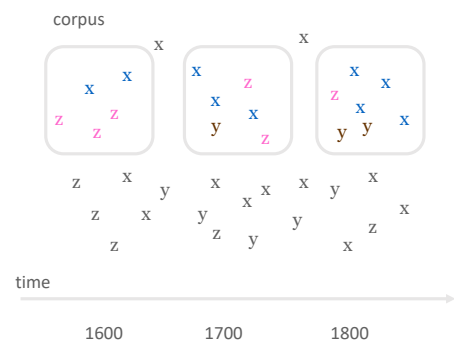

FIGURE 9

We can examine the collocates that a construction has in the 16oos, and we can ask whether they are the same as the ones that we find in the 170os and in the 1800 s. We can identify elements that have become more or less frequent 


\section{How does it work?}

- Collocate frequencies are compared against the overall frequencies of the construction

\begin{tabular}{c|c|c|c} 
be going to & say & other verbs & totals \\
\hline $1710-1780$ & 12 & 217 & 229 \\
\hline $1780-1850$ & 21 & 508 & 529 \\
\hline $1850-1920$ & 43 & 1288 & 1331 \\
\hline totals & 76 & 2013 & 2089
\end{tabular}

- The method produces a ranked list of the most typical verbs for each investigated period

- Strength of association = collostructional strength

FIGURE 10

over time. We can identify elements that are typical for a particular section of the corpus, and we can draw conclusions from that.

The way it works in practice is that the collocate frequencies of a construction are compared against the overall frequencies of that same construction for each collocate that you observe. You see an example here of the be going to construction that is used with the verb say across three periods of time.

We observe the raw frequencies of say. They happen to increase. From 12 to 21 to 43 , but then you see that also the construction as a whole increases in frequency as well. It goes from about 230 examples to 530 examples to more than 1300 examples. So say goes up in frequency, but also the construction itself goes up in frequency. Does that mean that say becomes more or less attracted to the construction? Does that mean that the attraction stays at the same level? This is something that we can figure out on the basis of a statistical analysis that takes all the verbs and their frequencies into account. The method produces a ranked list of the most typical verbs for each investigated period. I have used the term collostructional strength without properly defining it. Collostructional strength would be the strength of association between a construction and a lexical item that occurs within it, as measured by a collocation statistic.

What does this type of analysis show? It determines the elements that are most typical for a construction in modern usage, when you analyze a synchronic corpus. Applied diachronically, we can also determine the most typical elements for a construction in any given historical period. The collocational preferences can be used to describe the modern semantics and how it came to be that way. That was important for me. One other thing that attracted me to the method was that if we find that there are systematic changes, that there are attracted sets of semantically related collocates, not just individual items, 
then that would suggest that there is a broader trajectory of semantic change going on that reaches beyond just individual words, individual histories of lexical items.

Why would this be useful? The method allows explorative analyses of constructions and their diachronic variation, how they have developed. More usefully perhaps, it allows us to test proposed semantic developments. I mentioned grammaticalization paths that thave been proposed for the development of future constructions. My idea was to go into the data and see if these proposals that have been made could be falsified or substantiated. This is especially useful if we want to distinguish between competing hypotheses, which you can often find in the grammaticalization literature. One account might claim that this future construction developed in this way, and another account might propose a very different semantic pathway. How do we decide between the two? This method actually can get to the bottom of what kind of meaning came first, what kind of meaning it developed later, and how it all ended up.

Semantic classes of distinctive verbs would indirectly reflect stages of grammaticalization paths that have been proposed for the development of future markers, for example, in the work by Joan Bybee and colleagues (1991, 1994), who have argued for a path from the meaning of intention to the meaning of future and from thereon to epistemic or speaker-oriented modality.

To give you a taste of how all of this can be applied to concrete case studies, let's look at an example. So far, I have exclusively shown you data from English, so I think it is high time to broaden the outlook a bit. You know that English has a future with the modal auxiliary will. What you perhaps do not know is that a small language close by, Danish, has a vil future as well. The word looks almost exactly the same, etymologically it is the same.

There are further parallels in that the construction in its synchronic usage shows a preference for certain types of verbs. It is highly productive. It is highly general, but there are preferences, there are asymmetries. The construction prefers abstract atelic verbal complements such as verbs like require. There is nothing dynamic or agentive about require. It is a state. A Danish verb that means 'to be' is also among the most attracted items.

My questions for this particular case study were the following: Can the semantic developments be described in terms of shifting collocational preferences? Were there certain semantic verb classes that were central to the development? Can the collocates address the hypothesis that future constructions of this kind develop out of markers of intention? That would be the default hypothesis. If we have a verb that means "want", then it is a marker of intention that may eventually shade off into a use that encodes just future time reference, so that also inanimate subjects can be. used with it. I can say things like, It will rain, which does not mean that It wants to rain, but rather that it will happen in the future. 


\section{Data}

- raw-text historical corpora

\begin{tabular}{l|c|c|c|c} 
Corpora & Century & Size & Search & Ex. \\
\hline ACOD & $12-14$ & $36 \mathrm{k}$ & vil, vill, & 99 \\
\hline DSST 1 & $15-16$ & $400 \mathrm{k}$ & wil, will & 642 \\
\hline DSST 2 & $17-18$ & $240 \mathrm{k}$ & & 408 \\
\hline Gutenberg & $19-20$ & $700 \mathrm{k}$ & & 999 \\
\hline Total & & $1.4 \mathrm{M}$ & & 2,148
\end{tabular}

FIGURE 11

Here's an overview of the kind of data I used. A collostructional analysis does not require you to have millions and millions of words. In this case, I had four different historical periods ranging from the 12th to the 2oth century. It is a long and thin corpus really, with all in all about 1.4 million words. That, by today's standards, is considered very small. I looked for different orthographic variants of the auxiliary. I had a total of some 2000 examples to work with.

\section{Absolute frequencies}

\begin{tabular}{|c|c|c|c|c|c|c|c|c|c|c|c|}
\hline \multicolumn{3}{|c|}{ ACOD (12-14) } & \multicolumn{3}{|c|}{ DSST (15-16) } & \multicolumn{3}{|c|}{ DSST (17-18) } & \multicolumn{3}{|c|}{ Gutenberg (19-20) } \\
\hline Verb & Gloss & $\mathrm{N}$ & Verb & Gloss & $\mathrm{N}$ & Verb & Gloss & $\mathrm{N}$ & Verb & Gloss & $\mathrm{N}$ \\
\hline give & give & 9 & vare & be & 44 & have & have & 27 & vare & $b e$ & 126 \\
\hline have & have & 9 & gøre & $d o$ & 42 & vare & $b e$ & 27 & sige & say & 84 \\
\hline tage & take & 8 & give & give & 38 & gore & $d o$ & 20 & have & have & 82 \\
\hline vide & know & 5 & have & have & 31 & sige & say & 20 & blive & become & 41 \\
\hline lade & let & 4 & sige & say & 26 & give & give & 19 & se & see & 29 \\
\hline soge & seek & 4 & lade & let & 19 & gå & $g o$ & 11 & gà & $g o$ & 27 \\
\hline fare & travel & 4 & blive & become & 16 & bevise & prove & 10 & gøre & $d o$ & 21 \\
\hline gore & $d o$ & 3 & tale & talk & 15 & lade & let & 10 & fà & get & 19 \\
\hline svare & answer & 3 & bevise & prove & 10 & tro & believe & 10 & tage & take & 19 \\
\hline mæle & speak & 2 & ride & ride & 10 & forlade & forgive & 9 & komme & come & 14 \\
\hline bytte & swop & 2 & skrive & write & 10 & komme & come & 9 & finde & find & 13 \\
\hline
\end{tabular}

FIGURE 12

When we examine the absolute frequencies of the most frequent collocates across the four periods, there are already a few observations that we can make.

For example, there is a verb meaning "give", which is the most frequent one in the first period, after which it decreases. Eventually it disappears from the list of the most frequent elements.

In the opposite direction, there is a verb meaning "say" that does the exact opposite. First, it is not among the most frequent verbs, but then it gradually works its way up the list. In the last period it is on position two. But overall, 


\section{Decrease of give}

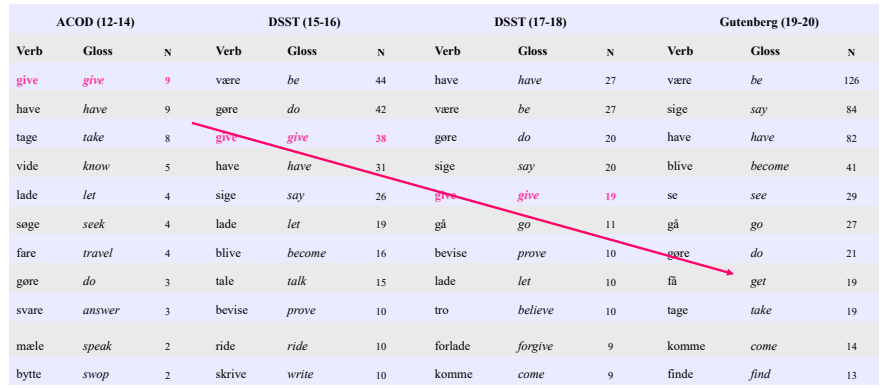

FIGURE 13

\section{Increase of sige}

- (det vil sige - that is to say, that means)

\begin{tabular}{|c|c|c|c|c|c|c|c|c|c|c|c|}
\hline \multicolumn{3}{|c|}{$\operatorname{ACOD}(12-14)$} & \multicolumn{3}{|c|}{ DSST (15-16) } & \multicolumn{3}{|c|}{$\operatorname{DSST}(17-18)$} & \multicolumn{3}{|c|}{ Gutenberg (19-20) } \\
\hline Verb & Gloss & $\mathrm{s}$ & Verb & Gloss & $\mathrm{N}$ & Verb & Gloss & $\mathrm{N}$ & Verb & Gloss & $\mathrm{N}$ \\
\hline give & give & , & vare & be & 44 & have & have & 27 & vare & be & 126 \\
\hline have & have & 9 & gore & $d o$ & 42 & vare & be & 27 & - iोiा & say & 84 \\
\hline tage & take & 8 & give & give & 38 & gere & तo & 20 & have & have & 82 \\
\hline vide & know & 5 & have & have & $\pi$ & sige & say & 20 & blive & become & ${ }_{41}$ \\
\hline lade & let & 4 & - ताइए & say & 26 & give & give & 19 & se & see & 29 \\
\hline soge & seek & 4 & lade & let & 19 & $\mathrm{gå}$ & go & 11 & $\mathrm{ga}$ & go & 27 \\
\hline fare & travel & 4 & blive & become & 16 & bevise & prove & 10 & gore & $d o$ & 21 \\
\hline gere & do & 3 & tale & talk & 15 & lade & let & 10 & fă & get & 19 \\
\hline svare & answer & 3 & bevise & prove & 10 & tro & believe & 10 & tage & take & 19 \\
\hline mæle & speak & 2 & ride & ride & 10 & forlade & forgive & 9 & komme & come & 14 \\
\hline bytte & swop & 2 & skrive & write & 10 & komme & come & 9 & finde & find & 13 \\
\hline
\end{tabular}

FIGURE 14

when we examine the raw frequencies, most of what we see are highly frequent verbs, like have, like be, do, give, take, and go. These verbs, for the most part, do not have a whole lot of semantic substance, and thus they do not allow us to say much about how the construction develops semantically.

The absolute frequencies revealed some tendencies, but not tangible developments. There is a constant of light verbs with high absolute frequencies, which could be taken to suggest that the changes that happened were either non-substantial or unsystematic. These could be seen as chance fluctuations in the lexical domain. If I had been working with a raw-frequency approach, I would have given up at this point with the conclusion that nothing has happened. However, I was curious to see if the collostructional approach would yield a different outcome, which it actually does. 


\section{Distinctive collexemes}

\begin{tabular}{|c|c|c|c|c|c|c|c|c|c|c|c|}
\hline \multirow[b]{2}{*}{ Verb } & \multicolumn{2}{|c|}{ ACOD } & \multicolumn{3}{|c|}{ DSST 15-16 } & \multicolumn{3}{|c|}{ DSST 17-18 } & \multicolumn{3}{|c|}{ Gutenberg 19-20 } \\
\hline & Gloss & cs & Verb & Gloss & $\mathrm{cs}$ & Verb & Gloss & cs & Verb & Gloss & cs \\
\hline tage & take & 3.5 & ride & ride & 5,2 & bekende & confess & 2,9 & se & see & 6,7 \\
\hline fare & travel & 3,4 & skrive & write & 4.3 & bevise & prove & 2,8 & vare & $b e$ & 6,2 \\
\hline soge & seek & 2,8 & gore & do & 4.3 & tro & believe & 2,8 & sige & say & 4.3 \\
\hline bytte & swop & 2,7 & give & give & 3,8 & forlade & forgive & 2,5 & spille & play & 4,0 \\
\hline bøte & pay & 2,7 & antegne & note & 3.7 & fore & lead & 2,3 & blive & become & 3.5 \\
\hline fange & catch & 2,7 & forklare & explain & 3.7 & æde & eat & 2,3 & få & get & 3.4 \\
\hline lose & solve & 2,7 & råde & advise & 3.7 & nægte & deny & 2,3 & rejse & travel & 3.0 \\
\hline mæle & talk & 2,7 & slås & fight & 3.7 & skikke & send & 2,2 & finde & find & 2,8 \\
\hline rebe & tie & 2,7 & love & promise & 2,1 & vise & show & 2,2 & hore & hear & 2,8 \\
\hline vide & know & 2,6 & tale & talk & 1,9 & bo & live & 2,1 & bringe & bring & 2,4 \\
\hline
\end{tabular}

FIGURE 15

Here's a table with the distinctive collexemes for each of the four periods. For each period you see the elements that are maximally over-represented in that particular corpus period. Let me briefly go through the periods individually and point out some developments along the way.

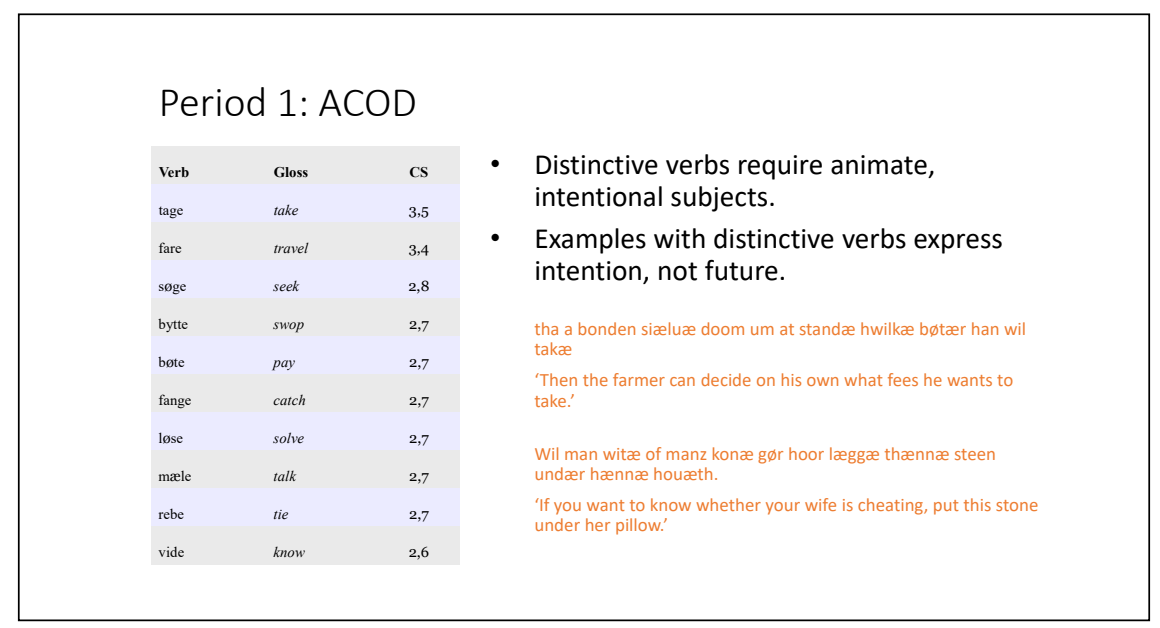

FIGURE 16

In the first period, this is Old Danish, as it was written between the 12th and 14th century. We find exclusively verbs that require animate intentional subjects, things like take, travel, seek, pay and catch. Human beings can do that, inanimate beings cannot. If we are examining the examples with distinctive verbs, we find that these examples express intention, not future. We have things like The farmer can decide what fees he will take, that is, what fees he wants to take. 


\section{Period 2: DSST 1}

$\begin{array}{lll}\text { Verb } & \text { Gloss } & \text { CS } \\ \text { ride } & \text { ride } & 5,2 \\ \text { skrive } & \text { write } & 4,3 \\ \text { gøre } & \text { do } & 4,3 \\ \text { give } & \text { give } & 3,8 \\ \text { antegne } & \text { note } & 3,7 \\ \text { forklare } & \text { explain } & 3,7 \\ \text { råde } & \text { advise } & 3,7 \\ \text { slås } & \text { fight } & 3,7 \\ \text { love } & \text { promise } & \mathbf{2 , 1} \\ \text { tale } & \text { talk } & \mathbf{1 , 9}\end{array}$

- Metalinguistic verbs and speech act verbs form a semantically coherent group.

Men her om vil ieg videre tale vdi den siette Artickel 'But I will further talk about this in the sixth article.'

- Other distinctive verbs express intentional actions and allow future interpretations.

That will happen in the future, but the main idea is intention or volition. I love this example here: If you want to know whether your wife is cheating, put this stone under her pillow. If you want to know, you will know eventually. I am not exactly sure what's supposed to happen with that stone, though.

Moving on to Period 2, we find that the profile of verbs changes in that we see an over-representation of verbs that are metalinguistic, that encode speech acts. There are quite a few of them here. We have write, note, explain, advise, promise and talk, among the most attracted ones. There are a few other distinctive verbs that express intentional actions and that allow a future interpretation. The top collocate here is the word that means "ride", as in ride a horse. The relevant example that you have at the bottom of the slide here translates as "I want to ride against the Kaiser with my sons". Someone wants to do something, but it is also clear that this will happen in the future. This you can see as the future interpretation making inroads and establishing itself more strongly across the semantic spectrum of the construction.

In the last period, this trend of speech act verbs being strongly represented continues. Speech act verbs are still the largest coherent group of distinctive collexemes. The verbs confess, deny, or forgive express actions that you do linguistically, but the interesting thing that we see in Period 3 is the first occurrence of inanimate subject referents: If your sins are about to lead you into desperation. Your sins do not want anything. Your sins are actions, not intentional beings. 


\section{Period 3: DSST 2}

$\begin{array}{lll}\text { Verb } & \text { Gloss } & \text { CS } \\ \text { bekende } & \text { confess } & 2,9 \\ \text { bevise } & \text { prove } & 2,8 \\ \text { tro } & \text { believe } & 2,8 \\ \text { forlade } & \text { forgive } & 2,5 \\ \text { føre } & \text { lead } & 2,3 \\ \text { æde } & \text { eat } & 2,3 \\ \text { næegte } & \text { deny } & 2,3 \\ \text { skikke } & \text { send } & 2,2 \\ \text { vise } & \text { show } & 2,2 \\ \text { bo } & \text { live } & 2,1\end{array}$

- Speech act verbs still the largest coherent group of distinctive collexemes

- First occurrence of inanimate subject referents

Dersom dine Synder vil føre dig til

Fortvivlelse, ...

'If your sins are about to lead you into desperation, ...'

\section{Period 4: Gutenberg}

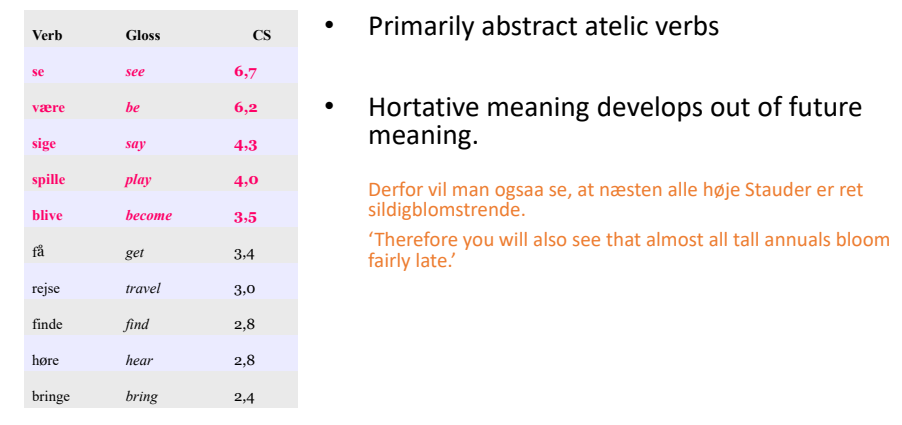

FIGURE 19

Finally, in the fourth period, which represents Present-day Danish, we see the profile that we are used to seeing in modern usage of the construction. The top collexemes are abstract atelic verbs, like see, be and say. There are a couple of others, and there are even extensions out of future meaning. There is a certain type of meaning that we can call hortative, which encourages someone else to do something. This occurs primarily in the context of see, if you will see. You will see that almost all tall annuals bloom fairly late. This is someone who is giving a piece of advice and who's inviting someone else to take this particular point 
of view. That is something that does not necessarily encode future time, but it is an extension out of that temporal meaning.

What can we conclude from this? These data are corroborating the idea that future meaning with this construction developed out of intentional meaning. We see that very firmly ingrained in the construction's profile early on. You could say this is something that has been predicted all along, and we have lots of typological evidence for this particular pathway. What is the big deal? I would say the big deal is that the corpus-based material gives us a lot more detail than secondary resources that we can glean from descriptive grammars or even from native speaker's intuitions. One thing that definitely goes beyond the generic story of future tense development that has been proposed in grammaticalization studies is that we have this group of speech act verbs, which seem to be central to the development of this construction here.

There is a second example that I want to mention. For that, we will go from will futures to be going to futures. There is the English be going to future of course, but there is another small language close by, Dutch, which has its own be going to future, even though that form is a little different. It is not a progressive going type form, but it is a basic verbal form of a verb (gaan) that means 'go'.

These two constructions, Dutch gaan and English be going to, are often seen as more or less equivalent. They translate into each other. I can say "It is going to rain tomorrow" and there is an equivalent sentence in Dutch. I can say "This is what we are going to do". Again, there is a way to say that in Dutch. If I say "I think that is going to happen" with an inanimate subject, also this I can translate into Dutch almost word for word. The constructions share characteristics such as an orientation to the present, a preference for intentional or premediated actions, and there is a preference for dynamic events as opposed to the stative and atelic predicates that will in English prefers.

That was my starting point. I thought this would be a good opportunity to develop a parallel case study, but then I looked at corpus data, and mutual translations of these two constructions. I examined corpus data from European Parliament Proceedings, which features speeches that are held in different languages and which are translated into several other European languages. The same text is thus available in different languages.

I looked at a data set of more than 7500 examples of be going to. Out of those 7500 there are only about 1000 that are translated into Dutch with gaan. That is $15 \%$, which is not much. Had it been half, I would have suspected a stylistic reason, so that translators want to avoid colloquialisms and therefore choose the more conservative construction with will. A rate of $15 \%$ however suggests 
to me that the two constructions are functionally different. It also made me wonder how much overlap I should expect in the first place.

I looked at two other future constructions that are not etymologically related and that would not be considered as translational equivalents. I looked at the will future and the Dutch zullen future, which is etymologically related to English shall. I took a smaller sample of 500 examples, and I found 215 translations with zullen, so $43 \%$. The overlap between these unrelated construction is significantly larger than the overlap that we find between be going to and gaan.

That sparked my interest. What semantic characteristics of be going to and gaan work against a mutual translation in present-day usage? Why are they not translated into each other more than they are? Second, did the two constructions drift apart only recently, or did they grammaticalize in different ways? That would be something of a surprise, because movement-based futures are thought to develop along similar lines.

My analysis was based on synchronic and diachronic corpus resources from English and Dutch. For modern English, I used the British National Corpus (BNC), a 100 million words corpus. For the historical part, I use the CLMET, which is a 9.5 million words corpus. I also used the Oxford English Dictionary, the source that Michael Israel used for the way-construction. The corpora for Dutch are smaller. The modern data comprise about 8 million words and the historical data from the Project Gutenberg hold about 4 million words. I exhaustively retrieved all examples with going to and gonna plus infinitive, and then the Dutch forms of the verb gaan, for which there are several morphologically inflected variants. I analyzed the data both in a synchronic way, with a collexeme analysis, and then diachronically with a diachronic distinctive collexeme analysis.

Comparing the collexemes

\begin{tabular}{lcllc}
\multicolumn{2}{c}{ be going to } & & gaan \\
Verb & CollStr & Verb & Gloss & CollStr \\
do & Inf & regenen & rain & 73.56 \\
get & Inf & praten & talk & 32.80 \\
happen & Inf & gebeuren & happen & 32.02 \\
say & 168.39 & kosten & cost & 29.42 \\
die & 125.70 & waaien & storm & 26.26 \\
cost & 93.45 & werken & work & 25.56 \\
put & 91.57 & samenwerken & collaborate & 21.81 \\
ask & 59.91 & zitten & sit & 18.83 \\
go & 58.13 & onderzoeken & analyze & 18.52 \\
marry & 52.95 & schijnen & shine & 17.99
\end{tabular}

FIGURE 20 


\section{Overlap}

\begin{tabular}{lcllll}
\multicolumn{2}{c}{ be going to } & \multicolumn{3}{c}{ gaan } \\
Verb & CollStr & Verb & Gloss & CollStr \\
do & Inf & regenen & rain & 73.56 \\
get & Inf & praten & talk & 32.80 \\
\cline { 1 - 1 } happen & Inf & gebeuren & happen & 32.02 \\
\cline { 1 - 1 } say & 168.39 & kosten & cost & 29.42 \\
die & 125.70 & waaien & storm & 26.26 \\
\cline { 1 - 1 } cost & 93.45 & werken & work & 25.56 \\
put & 91.57 & samenwerken & collaborate & 21.81 \\
ask & 59.91 & zitten & sit & 18.83 \\
go & 58.13 & onderzoeken & analyze & 18.52 \\
marry & 52.95 & schijnen & shine & 17.99
\end{tabular}

FIGURE 21

Let me show you the synchronic results first. On this slide, you see two lists with the synchronic collexemes of be going to and gaan. The lists show the most attracted lexical verbs for both be going to and gaan.

Among the top collexemes, there are exactly two verbs that match. With be going to, we have happen and cost. With gaan, we have two Dutch verbs that also mean "happen" and "cost", but that is where the similarities end.

Weather phenomena

\begin{tabular}{lc}
\multicolumn{2}{c}{ be going to } \\
Verb & CollStr \\
do & Inf \\
get & Inf \\
happen & Inf \\
say & 168.39 \\
die & 125.70 \\
cost & 93.45 \\
put & 91.57 \\
ask & 59.91 \\
go & 58.13 \\
marry & 52.95
\end{tabular}

\begin{tabular}{|c|c|c|}
\hline & gaan & \\
\hline Verb & Gloss & Collstr \\
\hline regenen & rain & 73.56 \\
\hline praten & talk & 32.80 \\
\hline gebeuren & happen & 32.02 \\
\hline kosten & cost & 29.42 \\
\hline waaien & storm & 26.26 \\
\hline werken & work & 25.56 \\
\hline samenwerken & collaborate & 21.81 \\
\hline zitten & sit & 18.83 \\
\hline onderzoeken & analyze & 18.52 \\
\hline schijnen & shine & 17.99 \\
\hline
\end{tabular}

FIGURE 22

It is instructive to look at the different verb types that we find across the two constructions. In Dutch, there are quite a few weather phenomena, such as rain, storm, and shine. That is not the typical kind of verb that you expect to see with a movement-based future. Rain is not an intentional agent, it is a natural phenomenon. 


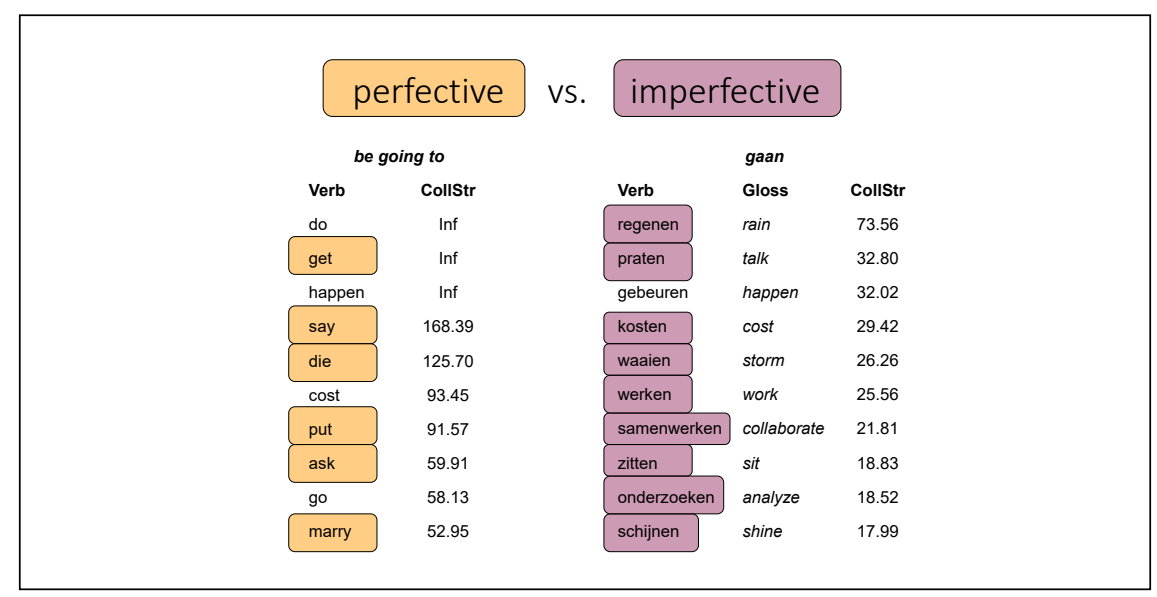

FIGURE 23

What struck me more though is that there is a great asymmetry with regard to the lexical aspect of verbs that we find in either construction. Be going to has a strong preference for verbs that I describe here as perfective. They encode a particular start point or end point, or they are even just happening at one singular point in time. Consider a verb such as get, which describes a punctual event. One moment you do not have it, then you get it, and then you have it. The same is true for the verb say. The verb die is perhaps the most drastic of them all. The verb marry also encodes a clear, punctual division of before and after.

With gaan, the most strongly attracted elements are imperfective. Rain can go on for a long time. Verbs such as talk, storm, work, collaborate, sit, or analyze encode activities that I can carry on and continue for an unlimited amount of time, or for as long as I choose to do so. That is one considerable difference.

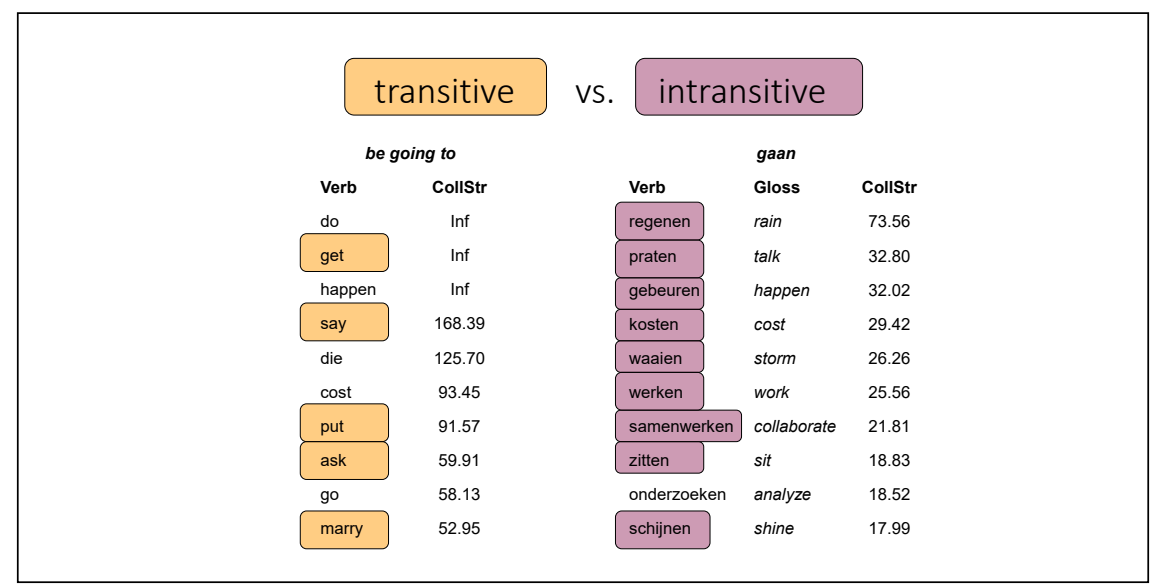


There is another difference in terms of transitivity. Be going to has a strong preference for transitive predicates. I get something, I say something, I put something somewhere, I ask someone, I marry someone. These are transitive verbs. The most attractive elements in the Dutch construction are intransitive, i.e. rain, talk, happen, cost, storm, work and so on and so forth.

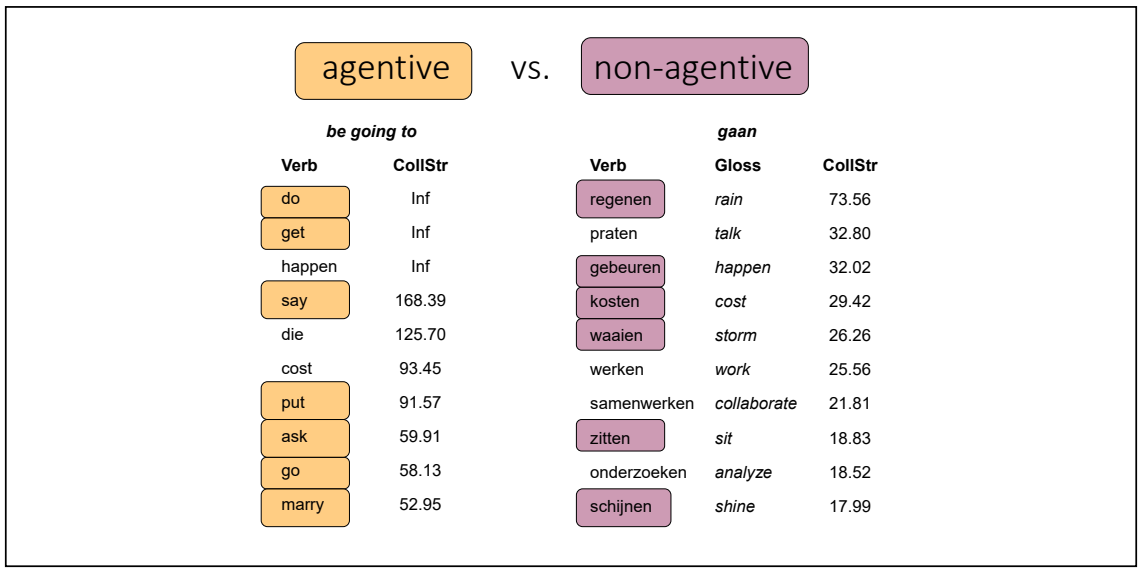

FIGURE 25

Another parameter that is strikingly asymmetric is agentivity: I do something actively, I get something, I say something, I put something somewhere. Things like rain or happen or sit are not agentive in the same way. There is no patient argument that would be affected by these activities.

To summarize, when we compare the collexemes, the main differences in synchronic usage are concerned with lexical aspect, transitivity and agentivity. These are aspects of transitivity that have been described famously in a paper by Hopper and Thompson (1980). I concluded that these grammatical differences really motivate the low rate of mutual translations. Grammatically, the two constructions both refer to future time events, but that is where the similarity ends. With regard to what kinds of events are encoded, the two constructions are almost diametrically opposed to each other, which brings me to the historical development. How did all this come to be? Let's look at the distinctive collexemes historically of English be going to.

This table shows you the overall development across the three periods with lists of the most attracted verbs for each historical time slice. Let me go through each period on its own.

We start with data in the 1700 s, so 1710 to 1780 . Here the most attracted collexemes encode intentional activities, and movement is often still a possible interpretation. When I am saying something like "You're going to fight for your country", you're not going to do it in your living room. You're going somewhere 


\section{English be going to}

\begin{tabular}{lcllll}
\multicolumn{2}{c}{ 1710-1780 } & \multicolumn{2}{c}{$1780-1850$} & \multicolumn{2}{c}{$1850-1920$} \\
Verb & CollStr & Verb & CollStr & Verb & CollStr \\
fight & 3.48 & hunt & 2.31 & be & 10.66 \\
publish & 2.32 & speak & 2.21 & do & 4.81 \\
answer & 1.94 & commence & 1.79 & get & 4.18 \\
observe & 1.94 & expose & 1.79 & have & 3.19 \\
embrace & 1.92 & part & 1.79 & try & 2.94 \\
ravish & 1.92 & strike & 1.79 & die & 2.30 \\
relate & 1.69 & & & stay & 1.76 \\
begin & 1.56 & & & happen & 1.74 \\
visit & 1.48 & & & run & 1.57 \\
& & & & talk & 1.37
\end{tabular}

English be going to

\begin{tabular}{|c|c|c|}
\hline \multicolumn{2}{|c|}{$1710-1780$} & \multirow{3}{*}{$\begin{array}{l}\text { - Intentional activities, movement } \\
\text { still a possible interpretation }\end{array}$} \\
\hline Verb & Collstr & \\
\hline fight & 3.48 & \\
\hline publish & 2.32 & \multirow{4}{*}{$\begin{array}{l}\text { And now my boy, I cried, you are going } \\
\text { to fight for your country. } \\
\text { I am going to visit the Marquis, and will talk } \\
\text { further with thee at my return. }\end{array}$} \\
\hline answer & 1.94 & \\
\hline observe & 1.94 & \\
\hline embrace & 1.92 & \\
\hline ravish & 1.92 & \multirow{4}{*}{ - Metalinguistic verbs } \\
\hline relate & 1.69 & \\
\hline begin & 1.56 & \\
\hline visit & 1.48 & \\
\hline
\end{tabular}

FIGURE 27

else to do the fighting. In "You're going to visit someone", it is implied that this visiting will take place somewhere else. Again, there are verbs that encode speech acts. There are a number of metalinguistic verbs that figure in this early period. Metalinguistic verbs feature in examples such as the story which I am going to relate or as he was going to begin his narrative. These verbs are attracted to be going to during this early period.

In the second period, all distinctive collexemes are compatible with intentional actions. Speech act verbs still continue to be represented. But we find the first events that are independent of human actions, as for instance the distinctive collexeme strike. While strike could be viewed as an agentive, intentional verbs that requires a human agent who is carrying out an action, the example on this slide shows a different meaning. In the example "When ten 
English be going to

$\begin{array}{lc} & \mathbf{1 7 8 0 - 1 8 5 0} \\ \text { Verb } & \text { CollStr } \\ \text { hunt } & 2.31 \\ \text { speak } & 2.21 \\ \text { commence } & 1.79 \\ \text { expose } & 1.79 \\ \text { part } & 1.79 \\ \text { strike } & 1.79\end{array}$

- All verbs compatible with intentional actions, speech act verbs still represented.

The orator had finished one story, and was going to commence another.

Are you going to speak to me, master?

- Events that are independent of human actions

In the true sleepy tone of a Scottish matron when ten o'clock is going to strike.

FIGURE 28

o'clock is going to strike", it is a clock doing the striking, not a human being. This opens up a pathway to other inanimate entities accomplishing actions, and eventually the construction broadens semantically.

English be going to

$\begin{array}{lcc}\text { Verb } & \text { • General, light verbs. } \\ \text { be } & \text { Collstr } & \text { G50-1920 } \\ \text { do } & 10.66 & \text { There is going to be some serious trouble here, I'll } \\ \text { get } & 4.81 & \text { lay my last dollar on that. } \\ \text { have } & 4.18 & \text { "What are you going to do?" asked George's } \\ \text { try } & 3.19 & \text { father. } \\ \text { die } & 2.94 & \text { Autonomous future events } \\ \text { stay } & 2.30 & \text { "Are we going to have an accident, Uncle Swithin?" } \\ \text { happen } & 1.76 & \text { In his small stock of knowledge, he knew, like all } \\ \text { run } & 1.74 & \text { around him, that he was going to die. } \\ \text { talk } & 1.57 & \text { Carrie was particularly excited, and said she hoped } \\ & 1.37 & \text { nothing horrible was going to happen. }\end{array}$

FIGURE 29

Moving on to the third period, here we find again the present-day profile of what be going to is like. There are general light verbs such as be, do, get and have, and these encode at least to some extent autonomous future events that haven't been planned and that haven't been executed by evolutional agents. Examples like "Are we going to have an accident" appear in the form of a question, "He knew that he was going to die" or "She hoped nothing horrible was going to happen" encode spontaneous or hypothetical events. Examples of this kind are over-represented in this last period. In the shifting patterns of collocations, we can thus see a development towards more abstract meanings. 
Also with be going to, the intentional source of future meaning seems very solid as a hypothesis. Speech act verbs as prototypical intentional verbs are central. The development towards future meaning is accompanied by a growing preference for general light verbs. All in all, this corroborates existing accounts of the grammaticalization of be going to.

Let's look at the diachrony of Dutch gaan. This slide shows an overview, but we are going to look at each period in turn.

Dutch gaan

\begin{tabular}{lllllllll}
\multicolumn{2}{c}{ 16th - 17th century } & \multicolumn{2}{c}{ 18th - 19th century } & \multicolumn{2}{c}{ 20th century } \\
Verb & Gloss & CS & Verb & Gloss & CS & Verb & Gloss & CS \\
lopen & walk & 3.52 & opzoeken & find & 2.67 & beminnen & love & 3.44 \\
strijken & run off & 3.30 & onderzoeken & analyze & 2.35 & denken & think & 3.44 \\
stellen & put & 3.25 & vertellen & tell & 2.25 & gebeuren & happen & 2.45 \\
reizen & travel & 2.86 & doorbrengen & spend & 2.01 & bevrijden & liberate & 1.96 \\
liggen & lie & 2.46 & geven & give & 1.68 & studeren & study & 1.96 \\
preken & preach & 2.00 & varen & travel & 1.68 & voelen & feel & 1.96 \\
treden & step & 2.00 & verkoopen & sell & 1.68 & eten & eat & 1.66 \\
verhuizen & move & 2.00 & leggen & put & 1.50 & werken & work & 1.49 \\
leiden & lead & 1.48 & sterven & die & 1.49 & krijgen & get & 1.47 \\
rechten & straighten & 1.48 & brengen & bring & 1.49 & twijfelen & doubt & 1.47 \\
spreken & speak & 1.41 & halen & get & 1.41 & kijken & look & 1.32 \\
drinken & drink & 1.36 & roepen & call & 1.39 & & & \\
bezigen & use & 1.33 & nemen & take & 1.37 & & &
\end{tabular}

FIGURE 30

Gaan unsurprisingly starts with predicates that are movement verbs such as walk, run off, travel, step and move, which are among the most strongly attracted elements in the first period. There are caused posture verbs like put or straighten. Most verbs have a imperfective aspectual profile, as for example walk or travel, which encode actions that you can continue for a long time. These verbs further encode intentional human actions.

Dutch gaan

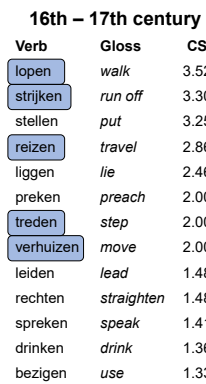

- Movement verbs

Nu willic gaan loopen al in mijn huus. now want.l go walk all in my house 'Now I want to go home.'

Daer gaet hij strijcken! there goes he run.off

'There he's running off!

- Caused posture verbs

- Most verbs are imperfective

- Intentional human actions 
Dutch gaan

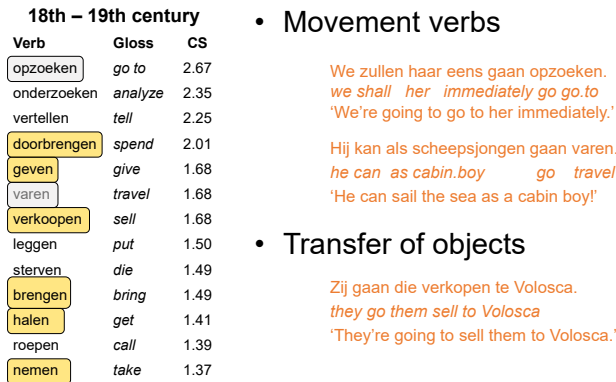

FIGURE 32

Dutch gaan

\begin{tabular}{|c|c|c|c|}
\hline \multicolumn{3}{|c|}{ 20th century } & \multirow{2}{*}{ - Cognitive and emotive verbs } \\
\hline Verb & Gloss & cs & \\
\hline beminnen & love & 3.44 & \\
\hline denken & think & 3.44 & Wat zou men wel gaan denken? \\
\hline gebeuren & happen & 2.45 & 'What is everybody going to think?' \\
\hline bevrijden & liberate & 1.96 & \\
\hline studeren & study & 1.96 & - gebeuren 'happen' \\
\hline voelen & feel & 1.96 & \\
\hline eten & eat & 1.66 & Wat gaat er dan gebeuren, Sander? \\
\hline werken & work & 1.49 & what goes there then happen Sander \\
\hline krijgen & get & 1.47 & 'What is going to happen then, Sander?' \\
\hline twijfelen & doubt & 1.47 & - mostly imperfective activities \\
\hline kijken & look & 1.32 & - often no intentionality \\
\hline
\end{tabular}

FIGURE 33

In the second period, movement verbs are still strongly represented. There is a verb that means "go to" and there is a verb that means "travel". Other distinctive collexemes encode transfers, as for example spend, or give, or sell, or bring. Suddenly these show up as a relatively homogeneous class. They are different in terms of their aspectual profile, as they have an endpoint. If you spend your money, then it is gone.

In the third period, the distinctive collexemes include cognitive and emotive verbs. A verb that means happen is another strongly attracted element. Most of the distinctive elements for this period are imperfective activities, typically with no intentionality at all. A verb like love encodes a human activity, but I can't intentionally decide to love someone, and when I love someone that is a state that has a temporal extension. That is very different from verbs such as 
break or cut. The list of verbs on this slide includes love, think, feel, and doubt, which form the profile of this movement-based future construction.

In summary, the early usages of gaan commonly involve literal, intentional motion. Later, movement verbs are joined by verbs of transfer. All along the constructional meaning broadens, accommodating verbs without the meaning of intentionality and then in present-day usage, gaan preferentially occurs with atelic predicates, and intention is no longer a part of the constructional semantics. In synchronic usage, we find weather verbs as attracted collexemes, and in the third historical period, these are cognitive response verbs such as doubt.

What can we conclude from all of this? English be going to and Dutch gaan both follow the general path of movement-based future constructions, which start with the idea of motion, then merge into the idea of intention, and finally settle into future time reference. Even though they are moving along the same path that is typologically well-attested, this does not mean that they function similarly in language use. They have converse preferences for perfectivity, transitivity, and agentivity. If we are looking at the collocational patterns in their shifts, we see substantial developmental differences. Be going to has a preference for speech act verbs in the second period. Gaan starts out with movement verbs that are imperfective like travel.

I have talked enough about future constructions for one day. To sum up, I hope you see what I find attractive about the concept of looking at shifting patterns of associations. If you come to it for the first time you might think that this gives you a very diffuse idea of how language changes. Wouldn't it be much clearer to look at morphosyntactic changes or at first instances of a construction with a tangible meaning difference? I think that the study of collocational shifts can yield important insights.

I would submit that shifts in collocational preferences constitute one central type of change in the network of constructions. I have mentioned hostclass expansion as one important concept in this context. A construction increases its number of links either to lexical collocates or to syntactic carrier phrases, constructions. I have argued that shifting collocational preferences can actually reflect systematic patterns of semantic change with a sufficient amount of accuracy, so that we can test hypotheses or test claims that have been proposed about semantic change elsewhere. Collocational preferences change as a construction develops along a grammaticalization path. Different paths then are embodied or realized by collocational changes that differ with respect to each other as well. With this, I would like to come to a close for today. Thank you for your attention. 